\title{
Market Readiness for Single-Use Cystoscopes According to Urologists and Procurement Managers Worldwide
}

\author{
Dinah Rindorf (D) \\ Sara Larsen' \\ Lotte Ockert' \\ Helene Jung ${ }^{2}$ \\ Claus Dahl ${ }^{3}$ \\ 'Ambu a/S, Ballerup, Denmark; \\ ${ }^{2}$ Department of Urology, Hospital \\ Lillebaelt, Vejle, Denmark; ${ }^{3}$ Department \\ of Urology, Capio Ramsey Santé, \\ Hellerup, Denmark
}

\begin{abstract}
Purpose: Single-use endoscopes have been subjected to increase awareness in recent years, and several new single-use cystoscopes (eg Ambu ${ }^{\circledR}$ aScope 4 Cysto) have entered the market. However, the market readiness for such single-use cystoscopes remains unknown. This study investigates the worldwide market readiness for single-use cystoscopes among urologists and procurement managers (PMs) from Europe, Japan, and the US.
\end{abstract}

Materials and Method: An online survey using QuestionPro ${ }^{\circledR}$ was distributed to urologists and PMs in France, Germany, Italy, Japan, Spain, the UK, and the US between March 10, 2020 and July 14, 2020. All surveys were translated into the respective local language. Statistical analyses were performed using the software package Stata/SE version 16.1, StataCorp. Fisher's exact test was used to analyze categorical variables and simple linear regression was applied to continuous variables.

Results: A total of 415 urologists and PMs completed the survey (343 [82.7\%] urologists and 72 [17.3\%] PMs). Seventy (16.9\%) were from Japan, 100 (24.1\%) were from the US, and 245 (59.0\%) were evenly distributed across the following European countries: France, Germany, Italy, Spain, and the UK. On average, respondents indicated that they would consider converting to single-use in $44.5 \%$ of their cystoscopy procedures. Respondents anticipated significantly higher conversion $(\mathrm{p}<0.05)$ when they $(1)$ used single-use ureteroscopes in their department, (2) were concerned about cystoscopy-related infection as a result of contaminated cystoscopes, (3) were members of their institution's value committee, or (4) considered cost-transparency to be important when purchasing cystoscopes.

Conclusion: This study investigated the marked readiness for single-use cystoscopes according to urologists and PMs worldwide. Respondents indicated a willingness to convert to single-use cystoscopes in nearly half $(44.5 \%)$ of their cystoscopy procedures. Respondents that were concerned about cystoscopy-related infections as a result of contaminated cystoscopes indicated a significantly higher anticipated conversion rate $(\mathrm{p}<0.05)$.

Keywords: single-use, cystoscopy, market readiness, single-use endoscopes, cystoscopyrelated infection, urologist

\section{Introduction}

Cystoscopy is one of the most common procedures in urology practices, and is considered safe. Both rigid and flexible cystoscopes can be used for cystoscopy procedures. Flexible cystoscopes are used for diagnostics, treatment, and control of both malignant and benign disorders of the lower urinary tract and are often utilized in outpatient clinics. However, reusable flexible cystoscopes are often subject to delays or cancellation of cystoscopy procedures as cystoscopes become unavailable when out for reprocessing or repairs. ${ }^{1-4}$
Correspondence: Dinah Rindorf Ambu a/S, Baltorpbakken I3, Ballerup, 2750, Denmark

Tel +4550737830

Email dihr@ambu.com 
Moreover, reusable cystoscopes are typically associated with costly and labor-intensive reprocessing, high repair costs, ${ }^{1,3,5-7}$ and risk of cystoscopy-related transmission of pathogens. ${ }^{8-10}$ For this reason, single-use cystoscopes have been subject to increased awareness, with single-use flexible cystoscopes such as the $\mathrm{Ambu}^{\circledR}$ aScope 4 Cysto recently entering the market. The sterile single-use flexible cystoscope offers consistent quality with no need for reprocessing or repairs, and no risk of cross-contamination as the cystoscope is disposed of after each procedure. Single-use flexible ureteroscopes are already widely adopted within urology practices; however, the market readiness for the recently introduced single-use flexible cystoscopes remains unknown. Thus, this study investigates the worldwide market readiness for single-use flexible cystoscopes among urologists and procurement managers (PMs) from Europe, Japan, and the US. Our goal is to help inform decision-makers about the advantages associated with singleuse cystosopes and create transparency about the receptiveness of single-use cystoscopes within urology practices.

\section{Materials and Methods}

\section{Recruitment}

An online survey using QuestionPro ${ }^{\circledR}$ was distributed to urologists and PMs in France, Germany, Italy, Japan, Spain, the UK, and the US between March 10, 2020 and July 14, 2020. A third-party consultancy firm identified and contacted all respondents and assigned them compensation for replying to the survey, keeping the sender anonymous. The third-party consultancy firm were also responsible for obtaining informed consent from all respondents. All surveys were translated into the respective local language.

\section{Survey}

Respondents were excluded from the survey if they did not fall into the category of either a physician performing cystoscopies or a PM covering a urology department. The survey asked respondents to indicate how many of their cystoscopy procedures they would consider using a single-use cystoscope for. They were also asked demographic questions regarding their main setting of employment (eg hospital, clinic), the annual volume of cystoscopy procedures in their department, their gender, their role (if any) on value analysis committees, their department's current reprocessing setup, the cystoscope currently used by their department, and whether they currently use single-use ureteroscopes. Regarding current experiences with reusable cystoscopes, the survey included questions on the respondents' perceived contamination rate of cystoscopes and the related infection risk, as well as issues with availability and experienced loss of image quality or lack of appropriate maneuverability. The full survey can be found in Appendix 1.

\section{Statistical Methods}

All statistical analyses were performed using the standard software package Stata/SE version 16.1, StataCorp. Fisher's exact test was used to analyze the categorical variables and simple linear regression was applied to the continuous variables, with statistical significance considered at $\mathrm{p}<0.05$.

\section{Ethics}

In the legislation at $\S 14$, stk. 2 it says regarding research projects using questionnaires, that such research should only be submitted for ethical approval if the research project involves human biological material. ${ }^{11}$ Our study did not involve any data from human subjects, thus no International Review Board (IRB) review and approval was required. The study was performed in accordance with the Declaration of Helsinki and written informed consent was obtained from participants.

\section{Results}

A total of 415 urologists and PMs completed the survey, of whom 343 (82.7\%) were urologists and 72 (17.3\%) were PMs. Of the 415 urologists, 245 (59.0\%) were from European countries, seventy (16.9\%) were from Japan and 100 (24.1\%) were from the US. Among respondents from European countries, 45 were from Italy and 200 were evenly distributed between France, Germany, Spain, and the UK. Table 1 shows the country of origin and the occupation of the respondents. A total of $863(87.5 \%)$ of respondents were male 363 and 52 $(12.5 \%)$ were female. In addition, 178 (42.9\%) respondents were part of their institution's value analysis committee.

Table I Respondents' Country of Origin and Occupation

\begin{tabular}{|l|l|l|}
\hline Country & $\begin{array}{l}\text { Urologists, } \\
\mathbf{N}=\mathbf{3 4 3}\end{array}$ & $\begin{array}{l}\text { Procurement Managers, } \\
\mathbf{N}=\mathbf{7 2}\end{array}$ \\
\hline France & 40 & 10 \\
\hline Germany & 43 & 7 \\
\hline Italy & 36 & 9 \\
\hline Japan & 60 & 10 \\
\hline Spain & 33 & 17 \\
\hline United Kingdom & 43 & 7 \\
\hline United States & 88 & 12 \\
\hline
\end{tabular}




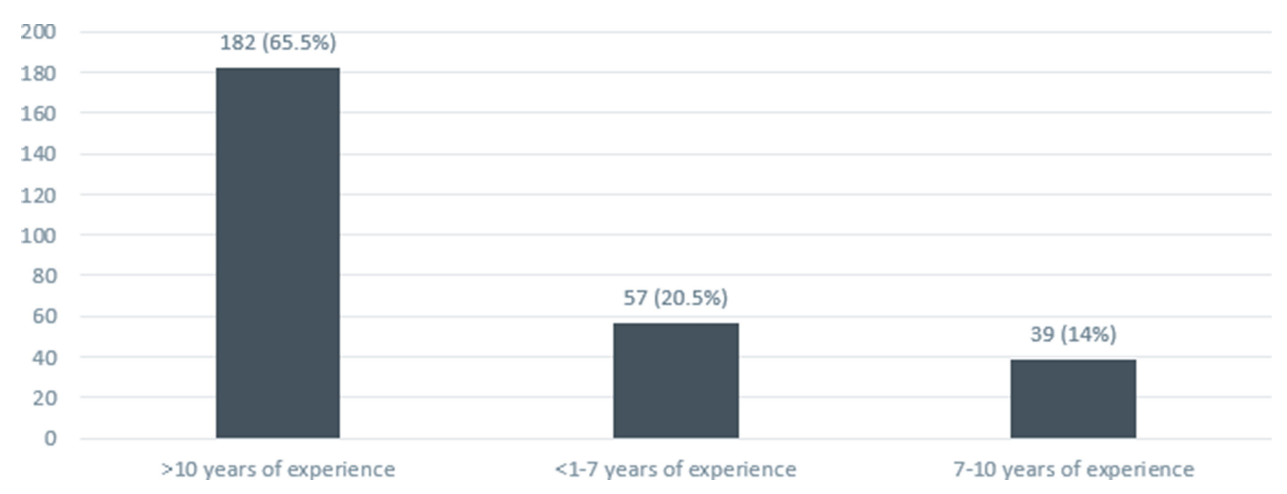

Figure I Urologists' experience performing cystoscopies (years).

Among the urologists, 278 (81\%) specified their number of years' experience performing cystoscopies. A total of 182 (65.5\%) had $>10$ years of experience, 57 (20.5\%) had $<1-7$ years and 39 (14.0\%) had 7-10 years (Figure 1).

The respondents were asked about the endoscopy cleaning process currently in use in their urology department. A total of 129 (38.0\%) used high-level disinfection (HLD), 116 (34.1\%) used sterilization, 83 (24.4\%) used chemical baths, and $12(3.5 \%)$ used Tristel wipes ${ }^{\mathrm{TM}}$ (Tristel Solutions Ltd., USA) as the primary cleaning process. When asked about their reprocessing setup, 227 (56.2\%) used local cleaning, 166 (41.1\%) used central cleaning, and $11(2.7 \%)$ used external cleaning (see Figure 2).

Regarding current experiences with reusable cystoscopes, $221(53.3 \%)$ indicated concern regarding cystoscopy-related infections as a result of using contaminated cystoscopes, and 276 (69.0\%) had experienced lost image quality or a lack of appropriate maneuverability of reusable cystoscopes. Finally, 213 (51.5\%) had used single-use ureteroscopes in their urology department.

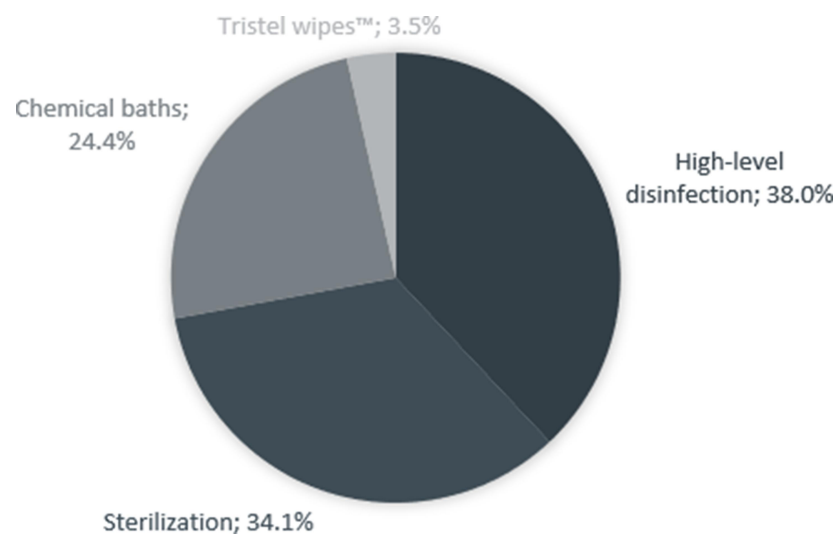

Figure $\mathbf{2}$ Split between cleaning processes currently in use in urology departments.
Significant differences in certain parameters were discovered between regions. On average, the respondents' oldest cystoscope in use was 6.2 years old. Amongst German respondents the oldest cystoscope in use was 7.6 years on average. On the other hand, the oldest cystoscope in use was 4.3 years on average amongst Japanese respondents. When looking at all European countries, the oldest cystoscope was on average 6.8 years and thereby significantly older than the oldest cystoscope in use reported by Japanese respondents $(p<0.001)$. The oldest cystoscope in use among American respondents was on average 1.7 years older compared to that of Japanese respondents $(p=0.014)$. Figure 3 illustrates the average age of the oldest cystoscope in use in each country compared to the overall average.

All respondents reported a conversion rate by anticipating the number of cystoscopy procedures, in percentage terms, for which they would consider using a single-use cystoscope. On average, the respondents indicated that they would consider converting to single-use in $44.5 \%$ of their cystoscopy procedures. Italian respondents reported the highest average conversion rate, at $57.5 \%$ of their procedures, while Japanese respondents reported the lowest average conversion rate, at $23.7 \%$. German respondents - who had been found to have the oldest cystoscopes in use-reported a significantly higher conversion rate

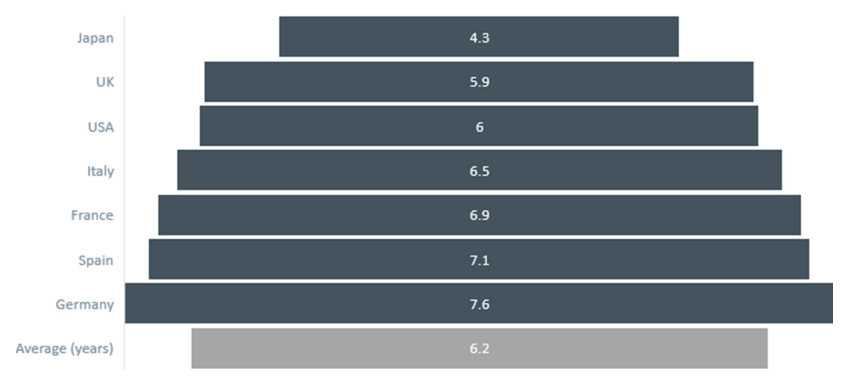

Figure 3 Oldest cystoscope (average) in use for each country. 


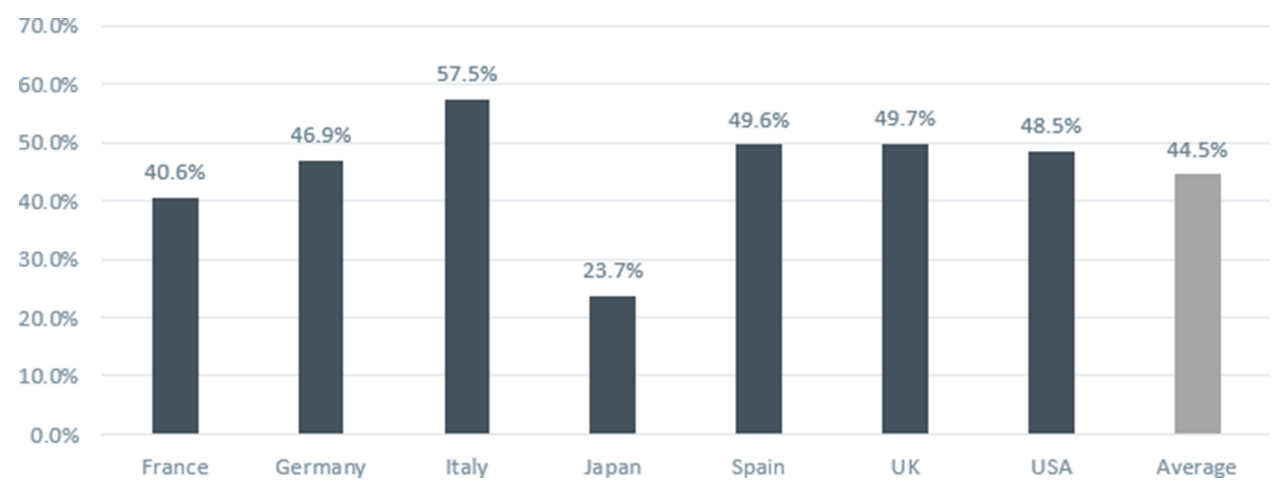

Figure 4 Average stated conversion rates from reusable to single-use cystoscopes by country.

compared to Japanese respondents, who had the youngest cystoscopes in use $(\mathrm{p}<0.001)$. Figure 4 shows the average stated conversion rate for each country.

Several factors revealed differences in conversion rates (see Table 2). Respondents whose department used external cleaning reported a higher conversion rate on average, as did respondents who often had to wait for a cystoscope to become available. However, the difference was not significant. Respondents who were part of their institution's value committee were more likely to indicate a higher anticipated conversion rate $(48.3 \%$ vs $41.6 \%$, $\mathrm{p}=0.044$ ). Likewise, respondents who used single-use ureteroscopes in their department, and respondents who indicated concern about cystoscopy-related infections as a result of using contaminated cystoscopes, were also more likely to indicate a higher anticipated conversion rate compared to those who did not use single-use ureteroscopes or did not express such concern (50.5\% vs $42.2 \%$, $\mathrm{p}=0.010$ and $50.5 \%$ vs $37.7 \%, \mathrm{p}<0.001$, respectively). Finally, respondents who indicated that cost transparency is important when purchasing cystoscopes were more likely to indicate a higher anticipated conversion rate compared to respondents who felt cost-transparency to be moderately or not important $(56.2 \%$ vs $42.3 \%, \mathrm{p}=0.002)$.

\section{Discussion}

To our knowledge, this study is the first to investigate market readiness for single-use cystoscopes according to urologists and PMs worldwide. Over a decade ago, the world's first single-use flexible bronchoscope was launched by Ambu A/S. Since then, single-use endoscopes have entered several endoscopy areas, including urology where single-use ureteroscopes are widely used today. With benefits such as cost-savings, ${ }^{12,13}$ as well as elimination of the risk of cross-contamination and need for frequent repair, single-use ureteroscopes are now widely adopted, whereas single-use cystoscopes have only recently been introduced.

In this study, we measured urologists' and PMs' willingness to adopt single-use cystoscopes, according to the

Table 2 Differences in Anticipated Conversion Rate Between Respondents

\begin{tabular}{|c|c|c|}
\hline & $\begin{array}{c}\text { Mean Conversion } \\
\text { Rate (\%) }\end{array}$ & Significance \\
\hline \multicolumn{3}{|c|}{ Does your urology department use single-use ureteroscopes? } \\
\hline Yes & 50.5 & $\mathrm{P}=0.010$ \\
No & 42.2 & \\
\hline
\end{tabular}

How often do you have to wait for a cystoscope to become available?

\begin{tabular}{|l|l|l|}
\hline Often & 46.5 & Not significant \\
Rarely or Never & 44.0 & \\
\hline
\end{tabular}

How important to you is cost transparency when purchasing cystoscopes?

\begin{tabular}{|l|l|l|}
\hline Important & 56.2 & $\mathrm{P}=0.002$ \\
Moderately important or & 42.3 & \\
not important & & \\
\hline
\end{tabular}

Are you in your institution's value analysis committee?

\begin{tabular}{|l|l|l|}
\hline Yes & 48.3 & $\mathrm{P}=0.044$ \\
No & 41.6 & \\
\hline
\end{tabular}

Have you ever been concerned about cystoscopy-related infections as a result of contaminated cystoscopes?

\begin{tabular}{|l|c|c|}
\hline Yes & $\begin{array}{l}50.5 \\
37.7\end{array}$ & $\mathrm{P}<0.00 \mathrm{I}$ \\
No & 54.1 & Not significant \\
\hline How is reprocessing currently conducted in your department? & \\
\hline Via external cleaning & 44.2 & \\
Via local or central & & \\
cleaning & &
\end{tabular}


respondents' anticipated number of procedures for which they would consider converting to single-use, as an indicator of the market readiness for single-use cystoscopes. The results indicate that urologists and PMs are willing to convert nearly half $(44.5 \%)$ of their procedures to singleuse cystoscopes on average. Factors affecting the respondents' anticipated conversion rate were identified using Fisher's exact test and simple linear regression.

Respondents' indication of willingness to convert nearly half of their procedures to single-use cystoscopes was obtained without their having experienced the performance of a singleuse cystoscopes for different procedures. Therefore, this assessment is based solely on a description of the benefits and features associated with single-use cystoscopes. Studies on the performance of single-use cystoscopes showing comparable $^{3,14}$ or even superior ${ }^{15}$ performance, as well as practical experience with single-use cystoscopes, may therefore have a positive effect on the willingness to convert to single-use.

Environmental impact should be considered when implementing new devices. Only a few studies have investigated the environmental impact associated with single-use endoscopes. ${ }^{16,17}$ For example, Davis et al found the carbon footprint of single-use ureteroscopes and reusable ureteroscopes to be comparable when accounting for manufacturing, sterilization, repackaging, repair, and solid waste disposal. ${ }^{17}$ To our knowledge, no studies have investigated the environmental impact of single-use compared to reusable cystoscopes. Hence, further studies should be conducted to estimate the environmental impact of disposable equipment and use of hazardous chemicals when reprocessing reusable cystoscopes.

In our study, the conversion rate was significantly higher among respondents who indicated concern regarding cystoscopy-related infections as a result of contaminated cystoscopes. Cystoscopes have been identified as "semicritical" devices that demand HLD between patients (according to the Spaulding Classification). Since cystoscopes are fragile mechanical instruments, reprocessing can be cumbersome and difficult to carry out successfully without compromising the quality of the disinfection. Moreover, multiple crosscontaminations have been documented related to reusable endoscopes. ${ }^{10,18-20}$ Single-use cystoscopes are sterile from the package, and converting to single-use cystoscopes therefore eliminates any chance of cross-contamination.

Our study found that the anticipated conversion rate was significantly higher among respondents who considered costtransparency to be important when purchasing cystoscopes. Several studies have investigated the per-procedure costs of
double-J stent removals with reusable cystoscopes. ${ }^{1,5-7}$ In a cost study conducted by Phan et al, the authors acknowledged limitations with regard to capturing incalculable hidden costs associated with failed cleaning cycles, potential contamination prior to use, etc. ${ }^{1}$ Compared to a reusable setup, single-use offers a more streamlined process with no hidden costs associated with labor time, reprocessing equipment, and repairs, making the per procedure cost more transparent in a single-use setup.

We found that the age of the oldest cystoscope in use varied significantly when comparing countries in Europe, the US, and Japan. With an average of 7.6 years, Germany had the oldest cystoscopes in use and German respondents were significantly more likely to report a higher anticipated conversion rate compared to Japan, which had the youngest cystoscopes in use. A study by Usawachintachit et al suggested that longer procedure times associated with reusable ureteroscopes compared to single-use ureteroscopes are due to the noncompromised performance of single-use ureteroscopes as they are new for every use and not subject to cumulative wear and tear. ${ }^{21}$ Many reusable cystoscopes are designed to have a shelf-life of seven years, and performance associated with the risk of cumulative wear and tear should be considered when using cystoscopes older than the designed shelf-life.

Finally, we can only speculate on why respondents who were members of their institution's value analysis committee anticipated a significantly higher conversion rate compared to nonmembers. Baston et al found that patients that had undergone stent removal with the single-use Isiris ${ }^{\mathrm{TM}}$ (Coloplast, Denmark) cystoscope had a $33.5 \%$ reduction in emergency department attendance compared to the standard reusable cystoscope group, as in the former case stents were removed in a shorter period of time. ${ }^{2}$ These features might be especially relevant for respondents who are used to assessing products' overall value contribution to all stakeholders in an institution, as opposed to assessing value contributions in one or more individual settings.

\section{Conclusion}

This study investigated the market readiness for single-use cystoscopes by considering urologists' and PMs' willingness to adopt single-use cystoscopes, according to the respondents' anticipated number of procedures for which they would consider converting to single-use. The study found that respondents were willing to convert to single-use cystoscopes in nearly half $(44.5 \%)$ of their cystoscopy procedures on average. The findings also indicated that respondents anticipated 
a significantly higher conversion rate when they (1) used single-use ureteroscopes in their department, (2) were concerned about cystoscopy-related infection as a result of contaminated cystoscopes, (3) were members of their institution's value committee, or (4) considered cost-transparency to be important when purchasing cystoscopes.

\section{Abbreviations}

PM, procurement manager; HLD, high-level disinfection.

\section{Disclosure}

DKR, SL, and LKO are employed by Ambu A/S, Ballerup, Denmark.

$\mathrm{HJ}$ and $\mathrm{CD}$ are consultants for Ambu A/S, Ballerup, Denmark.

\section{References}

1. Phan YC, Cobley J, Mahmalji W. Cost analysis and service delivery on using isiris ATM to remove ureteric stents. $J$ Endoluminal Endourol. 2018;1(1):e3-16. doi:10.22374/jeleu.v1i1.5

2. Baston EL, Wellum S, Bredow Z, et al. Office-based ureteric stent removal is achievable, improves clinical flexibility and quality of care, whilst also keeping surgeons close to their patients. Cent Eur J Urol. 2018;71(2):196-201.

3. Doizi S, Kamphuis G, Giusti G, et al. First clinical evaluation of a new single-use flexible cystoscope dedicated to double-J stent removal (IsirisTM): a European prospective multicenter study. World $J$ Urol. 2017;35(8):1269-1275. doi:10.1007/s00345-016-1986-0

4. Canales BK, Gleason JM, Hicks N, et al. An Independent analysis of flexible cystoscope repairs and cost. J Uro. 2007;178(5):2098-2102. doi:10.1016/j.juro.2007.07.014

5. Pietropaolo A, Hughes T, Tear L, et al. Comparison of ureteric stent removal procedures using reusable and single-use flexible cystoscopes following ureteroscopy and lasertripsy: a micro cost analysis. Cent Eur J Urol. 2020;73(3):342-348.

6. Beebe SC, Jenkins LC, Posid T, et al. Single-use grasper integrated flexible cystoscope for stent removal: a micro-costing analysis-based comparison. $J$ Endourol. 2020;34(8):816-820. doi:10.1089/ end.2020.0144

7. Oderda M, Antolini J, Falcone M, et al. Cost-effectiveness analysis of a single-use digital flexible cystoscope for double $\mathrm{J}$ removal. Urol J. 2020;87(1):29-34. doi:10.1177/0391560319859797
8. Saliou P, Le Bars H, Fournier G, et al. Évaluation microbiologique de la désinfection des cystoscopes souples au CHRU de Brest de janvier 2007 à décembre 2014. Prog En Urol. 2016;26(2):103-107. doi:10.1016/j.purol.2015.10.012

9. Jimeno A, Alcalde MM, Ortiz M, et al. Brote de infecciones urinarias por Salmonella spp. tras manipulación cistoscópica. Actas Urol Esp. 2016;40(10):646-649. doi:10.1016/j.acuro.2016.02.005

10. Sorbets E, Evrevin M, Jumas-Bilak E, et al. An outbreak of Pseudomonas aeruginosa urinary tract infections following outpatient flexible cystoscopy. Am J Infect Control. 2019;47(12):1510-1512. doi:10.1016/j.ajic.2019.05.005

11. Retsinformation. Komitéloven. Available from: https://www.retsinfor mation.dk/eli/lta/2017/1083. Accessed April 15., 2021.

12. Taguchi K, Usawachintachit M, Tzou DT, et al. Micro-costing analysis demonstrates comparable costs for LithoVue Compared to reusable flexible fiberoptic ureteroscopes. $J$ Endourol. 2018;32 (4):267-273. doi:10.1089/end.2017.0523

13. Large T, Rivera $M$, Nottingham $C$, et al. Initial Experience with a novel single use disposable ureteroscopy: a prospective single arm 90-day trial of the Axis TM Ureteroscope. Urol Pract. 2020.

14. Talso M, Emiliani E, Baghdadi M, et al. The new grasper-integrated single use flexible cystoscope for double $\mathrm{J}$ stent removal: evaluation of image quality, flow and flexibility. World $J$ Urol. 2017;35 (8):1277-1283. doi:10.1007/s00345-016-1987-z

15. Scotland K, Wong VK, Chan J, et al. Evaluation of a single-use flexible cystoscope: a multi-institutional international study. J Endourol. 2020;34(9):981-986. doi:10.1089/end.2020.0002

16. Sørensen BL, Grüttner H. Comparative study on environmental impacts of reusable and single-use bronchoscopes. Am J Environ Prot. 2018. doi:10.11648/j.ajep.20180704.11

17. Davis NF, McGrath S, Quinlan M, et al. Carbon footprint in flexible ureteroscopy: a comparative study on the environmental impact of reusable and single-use ureteroscopes. $J$ Endourol. 2018;32 (3):214-217. doi:10.1089/end.2018.0001

18. Kenters N, Huijskens E, Meier C, et al. Infectious diseases linked to cross-contamination of flexible endoscopes. Endosc Int Open. 2015;3 (4):E259-265. doi:10.1055/s-0034-1392099

19. Larsen S, Russell RV, Ockert LK, et al. Rate and impact of duodenoscope contamination: a systematic review and meta-analysis. EClinicalMedicine. 2020;25:25. doi:10.1016/j.eclinm.2020.100451

20. Epstein L, Hunter JC, Arwady MA, et al. New Delhi metallo- $\beta$ lactamase-producing carbapenem-resistant escherichia coli associated with exposure to duodenoscopes. J Am Med Assoc. 2014;312 (14):1447-1455. doi:10.1001/jama.2014.12720

21. Usawachintachit $M$, Isaacson DS, Taguchi $K$, et al. A prospective case-control study comparing lithovue, a single-use, flexible disposable ureteroscope, with flexible, reusable fiber-optic ureteroscopes. J Endourol. 2017;31(5):468-475. doi:10.1089/end.2017.0027
Research and Reports in Urology

\section{Publish your work in this journal}

Research and Reports in Urology is an international, peer-reviewed, open access journal publishing original research, reports, editorials, reviews and commentaries on all aspects of adult and pediatric urology in the clinic and laboratory including the following topics: Pathology, pathophysiology of urological disease; Investigation and treatment of urological disease; Pharmacology of drugs used for the treatment of urological disease. The manuscript management system is completely online and includes a very quick and fair peer-review system, which is all easy to use. Visit http://www.dovepress.com/ testimonials.php to read real quotes from published authors. 